\title{
Tezaver slovenskega ljudskega jezika na Koroškem - dokaz živosti graške slavistike
}

\author{
LUDVIK KARNIČAR \\ Institut für Slawistik der Karl-Franzens-Universität Graz, Merangasse 70/I, \\ A-8010Graz,ludwig.karnicar@uni-graz.at
}

\begin{abstract}
Prispevek obravnava dolgoročni projekt inventarizacije slovenskega ljudskega jezika na avstrijskem Koroškem, ki je stekel pred tridesetimi leti na Inšitutu za slavistiko v Gradcu, in prikazuje v prvem delu napredovanje tezavra (do leta 2009 so bili izdani zvezki A do K, v pripravi je sedmi zvezek od L do M), v drugem pa kartografiranje posameznih diatopnih sinonimov na avstrijskem Koroškem.
\end{abstract}

The article deals with the long-term dialectological project of creating a lexical inventory of the Slovene Volkssprache in Carinthia and presents some results of this project: the work on the Thesaurus (as of 2009 six volumes from A to $\mathrm{K}$ have been published; the seventh volume, $\mathrm{L}-\mathrm{M}$, is currently in preparation) and the lexical cartography illustrating the spread of selected diatopic synonyms in Austrian Carinthia.

Ključne besede: leksikalna inventarizacija, tezaver, koroška slovenska narečja, graška slavistika

Key words: lexical inventory, Thesaurus, Slovene dialects in Carinthia, Slavic Studies in Graz

Prispevek se nanaša na napredovanje dolgoročnega raziskovalnega projekta Leksikalna inventarizacija slovenskega ljudskega jezika na Koroškem, katerega najvidnejši rezultat ostaja doslej tezaver, ki ga izdaja Avstrijska akademija znanosti (1. zv. A-B 1982, 2. zv. C-Dn 1987, 3. zv. Do-F 1992, 4. zv. G-H 1994, 5. zv. I-Ka 2007, 6. zv. Kd-Kv 2009, 7. zv. L-M v pripravi). Gre za slovar, ki ima v mednarodni slavistiki zasluženo ime in je nepogrešljiv pripomoček $\mathrm{v}$ slavistični primerjalni dialektologiji, etimologiji in onomastiki. 
Točno pred tridesetimi leti se je delovna skupina, zbrana okoli tedanjega predstojnika inštituta za slavistiko prof. Stanislava Hafnerja (1916-2006) in docenta Erika Prunča, ki je bil odgovoren za operacionalizacijo megaprojekta, zavedla znamenj časa, se pravi posledic neustavljivega korakanja asimilacije.

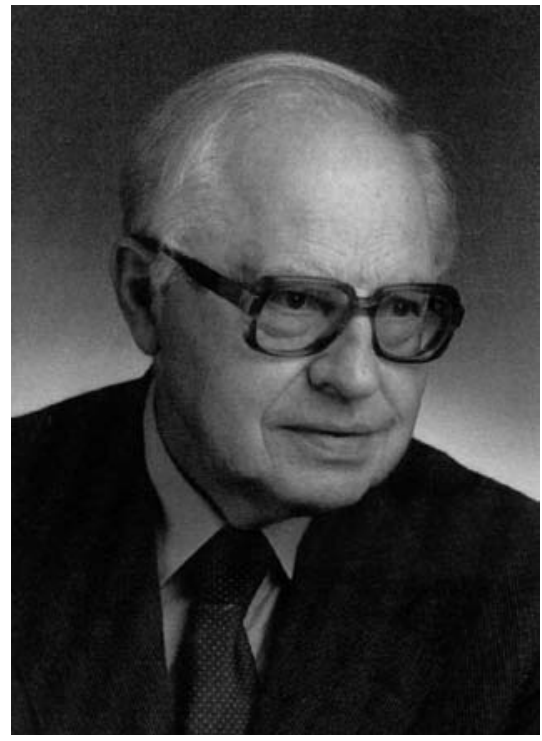

Stanislav Hafner (1916-2006)

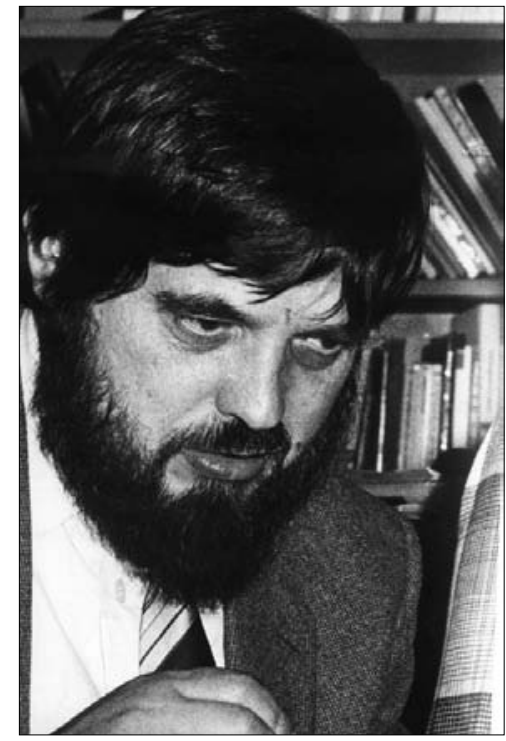

Erik Prunč

Že Urban Jarnik je ugotavljal, da germanizacija na Koroškem napreduje vsakih sto let za eno uro:

Da die neuere Kritik die Slawen nicht für dieslandige Urvölker will gelten lassen, sondern ihre Einwanderung erst in das sechste Jahrhundert festsetzt, so zählen wir von der Zeit ihrer Ankunft an 13, und von der Zeit der Anerkennung Fränkischer Oberherrschaft unter Boruth an elf Jahrhunderte. Man nehme nun diese Zahlen 13 oder 11 für eben so viele Stunden, und zähle sie von der heutigen Sprachgränze zurück gegen Norden bis an die Mur, und von Hermagor westlich hinauf bis nach Luggau, so hat die Annahme des Vorrückens Deutscher Sprache alle Jahrhundert um eine Stunde beinahe Gewissheit erlangt (Jarnik 1826).

Dandanes povzročajo germanizacijo mobilnost, vdor nemških medijev, psihološki in politični pritisk in nenavsezadnje tudi nesimpatičnost osrednjih manjšinskih organizacij, manjkajoča jezikovna in narodna zavest in še kaj, kar vodi v upadanje jezikovne kompetence in agonijo slovenščine na Koroškem.

Delovna skupina je tedaj priklicala v življenje kompleksen projekt, v sklopu katerega naj bi se tik pred dvanajsto odstranile zadnje bele lise na sicer dobro obdelanem zemljevidu koroških slovenskih govorov, in ne samo to. V skladu s sodobno dialektološko metodologijo je projekt obsegal pet ciljev (prim. Hafner, Prunč 1980): 
1. Iz živih govorov naj bi bili zajeti s tonskimi posnetki vsi glasoslovni pojavi (izoglose) dvojezičnega koroškega ozemlja, za kar je bilo izdelanih 128 vzorčnih stavkov.

2. Ugotovljen naj bi bil potek izbranih izoleks s kartami za ponazoritev razporeditve diatopnih sinonimov, kar ni nepomembno za kulturno zgodovino Koroške in tudi za znotrajslovansko primerjavo.

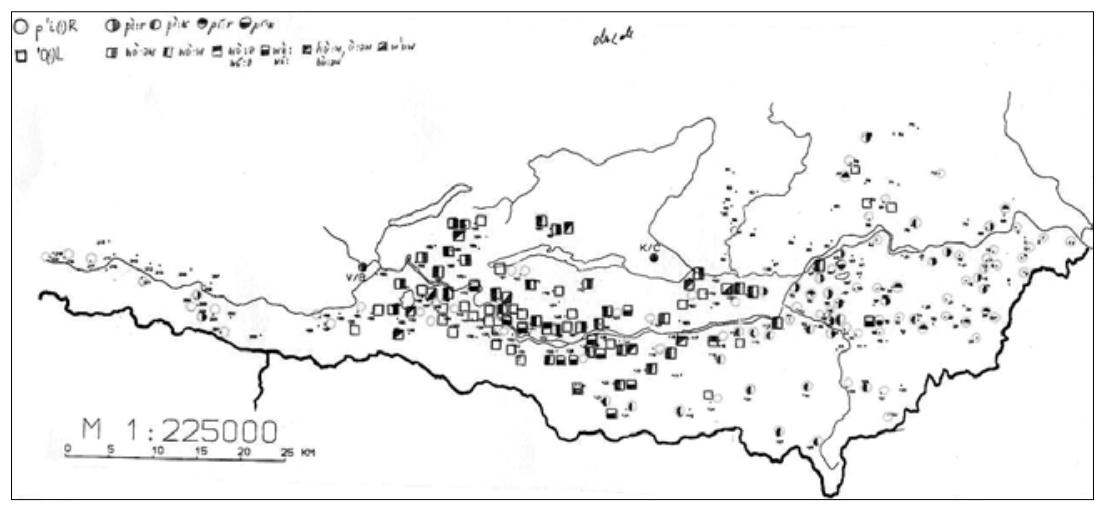

Ročno izdelana karta za germansko »ol« (Rož) in »pir« (drugod) - pivo

3. Od A do Ž naj bi izšel v približno 14 zvezkih tezaver, dvojezična slovenskonemška konkordanca, edinstvena v slovanski dialektologiji. Za to delo je bilo najprej treba ekscerpirati vso narečjeslovno koroško literaturo od Jarnika do Lauseggerjeve, kar pomeni, da so avtorji upoštevali več kot sto narečjeslovnih in etnoloških člankov in disertacij, tako da se je nabralo približno 600.000 alfabetsko urejenih listkov.
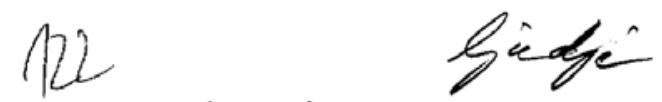

Zdáne dúšce.

\section{Se 50}

Lođi, qa mëjniče prestáwlījo, mórijja pu smfta té mëjniče prenášato. Pu noç jsh je šlošàta, qa wpijëja: „qám bom vtaqnủ, qám bom vtaqnù?“

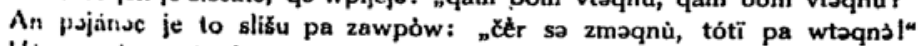
llüns se je nató ulıvásu: quíqa lit səm že mòw to vist na sabèl Tí sa ins pa vond’r puvédu, qám náj dim, pa me rišul ${ }^{u}$

Eden od približno 60 primerov za lemo ljudje (Slovenji Plajberk: Šašel - Ramovš, Narodno blago iz Roža, 1936-37)

Kar zadeva leme, je korpus zaključen; avtorji tezavra pa zavzemajo stališče tudi do aktualnega stanja besedišča, in sicer s tem, da sinonime, frazeme in derivate dodajajo iz lastne kompetence in iz terenskih posnetkov ter jih označujejo z zvezdico, nemške izposojenke pa označujejo že v iztočnici z leksikalno-semantičnimi kvalifikatorji od nič do pet. Gesla brez oznake so normalna, v splošni rabi, gesla s št. 1 so značilna za posamezna strokovna 
področja, gesla s št. 2 so prišla v govor iz šole in administracije, gesla št. 3 . so neologizmi ali primeri knjižne slovenščine, s št. 4 so označeni individualni neologizmi, 5 pa pomeni, da besede ni bilo mogoče uvrstiti v nobenega od navedenih kvalifikatorjev. Če torej nekdo prodaja sln. narečno besedo veter za nem. Wetter/vreme, je pomen označen s številko 5. Jasno je, da je bilo pri dodeljevanju navedenih petih kvalifikatorjev dosti kritičnega razmišljanja in obotavljanja.

Govori na Koroškem niso zanimivi le iz jezikoslovnih razlogov, ker ohranjajo zaradi periferne lege številne arhaizme, pač pa tudi v sociolingvističnem pogledu, saj zaradi kontaktnih pojavov predstavljajo eksemplaričen raziskovalni predmet. Slovenščina na Koroškem živi v dvojezičnih okoliščinah. Nemščina je prevladujoči jezik v upravi, šolstvu in drugod, slovenščina pa izpostavljena $v$ vsakdanjem občevanju velikemu nemškemu vplivu. To se odraža tudi v tezavru, tako da so nekatere besede, ki se začenjajo npr. na $\mathrm{A}$ in $\mathrm{F}$ zaradi predpon ajn-, ar- (ajnrajhati, arcelati), far-/for- (farpohtati,

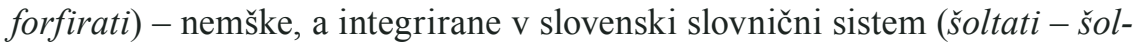
tovati, prešoltati, zašoltati se itd.).

4. Predvidena je bila še členitev posameznih besednih polj z že delno izdelano semantično vprašalnico »človek«.

5. Zadnja točka so bili avdiovizualni posnetki kompleksnih govornih položajev, etnografskih in kulturnozgodovinskih manifestacij z dokumentacijo materialne kulture, kar pa je presegalo realne možnosti projekta.

V začetku pa je bilo vsekakor treba vzpostaviti gosto omrežje z več kot 200 informacijskimi točkami od Potoč pri Labotu do Potoč pri Šmohorju - omrežje, iz katerega so bili že na voljo narečni podatki oziroma je bilo take pričakovati.

Začelo se je zelo obetavno, s sekretarko in petimi deloma honorarno zaposlenimi sodelavci, toda kmalu je bilo, kot pogosto v življenju, ugotovljeno, da so bili cilji zastavljeni previsoko. Za njihovo uresničitev bi moral biti projekt od vsega začetka institucionaliziran z najmanj štirimi celodnevno zaposlenimi sodelavci (eden zadolžen za teren, dva za znanstveno delo: sistematiziranje gradiva, transkribiranje, lematiziranje, semantiziranje in opisovanje trakov ter pripravo tezavra, četrti za tehnične naprave), tako pa so vsi honorarni sodelavci/ sodelavke - in doslej jih je bilo 13 (H. Pfandl, A. Sellner, B. Lex, M. Junker, N. Grilj, E. Schafzahl, U. Leiter-Köhrer, M. Polanz, T. Koren, A. Žejn, M. Trampusch, F. Hafner) - odšli, takoj ko so dobili socialno bolj perspektivno zaposlitev. Dotekajoča finančna sredstva so bila po letu 1985, ko smo izčrpali dolgoletno široko podporo Znanstvenega raziskovalnega sklada, žal za življenje premajhna. Poskus institucionalizirati projekt v sklopu Avstrijskega zakona o narodnih skupnostih v letu 1986 ni uspel. Ko se je po drugem zvezku poslovil še kolega Prunč in postal redni profesor na inštitutu za prevajalce in tolmače, se je celotno breme tako obsežnega podvzetja naslonilo v glavnem na šibka asistentska ramena pišočega.

A vendar. Kljub kadrovskim in finančnim težavam se je od zastavljenih ciljev doslej posrečilo uresničiti izdajo 6 zvezkov tezavra s ključem in s pomočjo 
vprašalnih listkov ter tonskih posnetkov sestaviti nekaj jezikovnogeografskih kart (12 v poskusnem zvezku 1980). To so kartografirani primeri domov, teden, grd, moliti, pomlad, zelje, zajtrk, žep, govoriti, polnočnica, teloh, zvonček, dve sta priloženi 6. zvezku tezavra (krompir, koruza), tri dodatne bodo pripete naslednjemu zvezku L-M (kositi, kosec, les), nadaljnjih 40 pa je že izdelala in pripravila kot disertacijo nadvse vestna sodelavka projekta in raziskovalka Andrejka Žejn.

Eden največjih problemov pri sestavljanju tezavra je bil tehnične narave: kako spraviti na računalnik 500 posebnih znakov, recimo nosni dolgi, široki cirkumflektirani $o$ v besedi golob, ko pa prvotno ni bilo na voljo niti strešic. Pri prvem zvezku je avtor prispevka na kseroksov iztis diakritične znake nad črko in pod njo vnašal kar ročno, kar je bilo najhitreje in brez težav pri tiskanju.

Drugi zvezek, tudi izdelan na kseroks, je doživel pravo pustolovščino. Potrebna je bila kodirna lista, tiskarna pa je bila prvič soočena s takimi hieroglilfi in zahtevnim konvertiranjem znakov. Pri vsaki korekturi so se pojavljale nove napake, tako da je zvezek romal med Gradcem in Dunajem cela tri leta in izšel šele leta 1987.

Računalniška tehnologija je medtem napredovala in naslednja dva zvezka sta bila izdelana s programom TEH, kjer se vsak posebni znak pojavlja v lomljenem oklepaju kot številka - pri e-ju in o-ju tudi po tri!

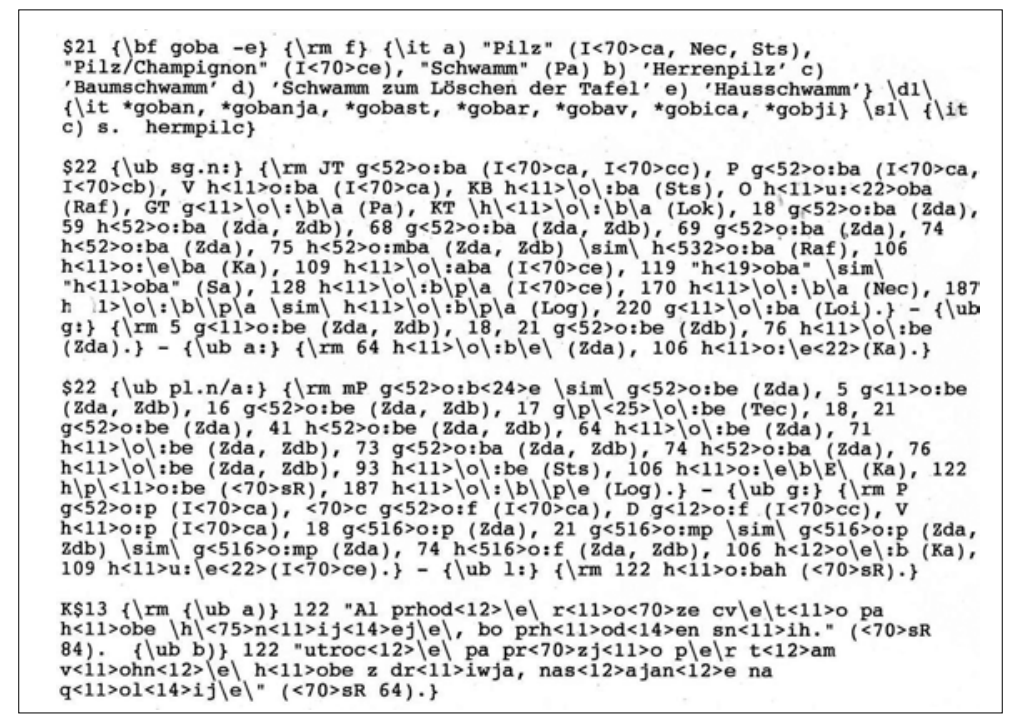

Kodiran primer "goba«

Za branje korektur je bilo to nemogoče, pri tisku pa zato ni bilo nobenih težav. Pri petem zvezku smo posebne znake kopirali iz razpredelnice in jih prenašali $\mathrm{v}$ dokument pa se veselili prve pisave, kjer je bilo razmerje med zaslonom in iztisom 1:1. Šesti in sedmi zvezek sta sestavljena s sistemom ZRCola. 
Tezaver nudi vpogled v geografsko razširjenost posameznih glasoslovnih in oblikoslovnih pojavov, tako nudi primer jagodica na razdalji dobrih $70 \mathrm{~km}$ med drugim sledeče glasoslovne oblike: jahuca, hahoca, waholca, jahotica, jatəhica, (j)ogadica, odgaca in ozgaca!

Iz zadnjega, šestega zvezka (kd-kv) sledijo primeri za dvo- in veččlenske izraze ter frazeme iz leme krava:

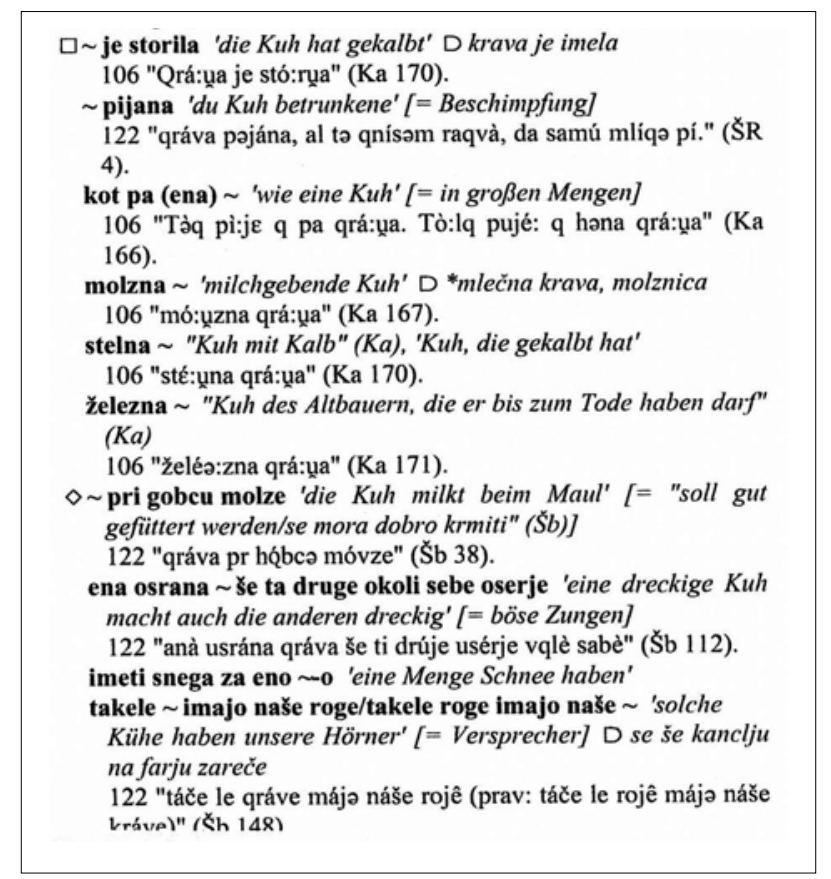

Tehničnemu napredku smo priča tudi pri izdelovanju kart. Pri prvih kartah je geograf na osnovno karto južne Koroške s pinceto lepil prozorne trikotnike, kvadrate in druge znake, zdaj pa kartografiranje poteka v sodelovanju z geografskim inštitutom Antona Melika na barvni računalniški karti z reliefom v sistemu GIS (Jerneja Fridl).

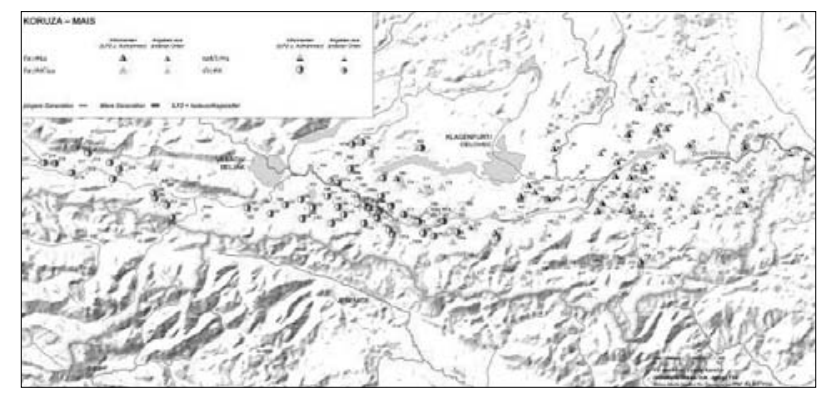

Karta je priložena 6. zvezku tezavra 
Napredek je torej viden na vseh ravneh in je povezan s prihodom Andrejke Žejn v Gradec, ko se je dogodil velik premik v pozitivno smer. Projekt je po dvanajstletnem hiranju ponovno zaživel. Zahvala gre triletnemu slovenskoavstrijskemu projektu ZRC SAZU in Balkanski komisiji Avstrijske akademije znanosti, prav tako Inštitutu za slavistiko v Gradcu, ki slej ko prej nudi delovne prostore - tam je tudi arhiv -, in ne nazadnje Slovenskemu znanstvenemu inštitutu na Dunaju, pri katerem je znanstvenica Andrejka Žejn zaposlena.

Iz navedenega ni težko spoznati, da tako zahtevno in drobnjakarsko delo ne more biti stvar univerz, pač pa edino le resnih raziskovalnih ustanov, kot so akademije in znanstveni inštituti. V upanju, da bo uvidevnost znanstvenih ustanov še trajala, bi bilo želeti, da bi bogati dialektološki arhiv s 600 urami posnetkov ne ostal neizkoriščen in da bi se koroškemu slovenskemu ljudskemu jeziku pravočasno postavil soliden znanstveni nagrobnik v obliki tezavra do črke $\breve{Z}$.

\section{LITERATURA}

Urban JARNIK, 1826: Andeutungen über Kärntens Germanisirung. Carinthia 16 (po: Baum Wilhelm (ur.), 2009: Urban Jarnik. Romantik, Nationalismus und Panslawismus in Kärnten. Klagenfurt - Wien. Kitab-Verlag. 88.

Stanislaus HAFNER, Erich PRUNČ (ur.), 1980: Lexikalische Inventarisierung der slowenischen Volkssprache in Kärnten (Grundsätzliches und Allgemeines). Graz: Institut für Slawistik der Universität Graz.

\section{THE THESAURUS OF SLOVENE DIALECTS IN CARINTHIA - AN INDICATION OF THE VITALITY OF SLAVIC STUDIES IN GRAZ}

The Slovene dialects in Austrian Carinthia are of special linguistic interest for a number of reasons. Historically, they bear testimony to important archaisms (remnants of nasal vowels, lexical items such as the Germanic ol for beer »ale«). Synchronically, the area is interesting because of its natural bilingualism and the German and Slovene interferences and language contacts. Today, Slovene dialects in Carinthia are threatened with extinction, being under pressure from German. Their exploration is therefore an urgent requirement and a question of time. Thirty years ago a working group of researchers into the Slovene language therefore began a long-term project of creating a lexical inventory of the Slovene dialects in Carinthia. The first goal that could be achieved successfully, despite personal and financial difficulties, was the edition of the bilingual SloveneGerman dictionary Thesaurus. A second aim is the lexical cartography of some diatopic synonyms, which is also a very important part of the project and aims at contributing to a better understanding of the cultural history of Carinthia, permitting a comparison of lexemes with other Slavic and neighbor languages. 